\title{
Effect of artificial saliva on the mechanical properties of a polymer material reinforced with fiber, used in esthetic tooth restorations
}

\section{Wpływ sztucznej śliny na właściwości mechaniczne materiału polimerowego wzmocnionego włóknem, stosowanego w estetycznych rekonstrukcjach zębów}

\author{
Rafał Brożek ${ }^{1, A-D}$, Krzysztof Pałka ${ }^{2, B}$, Ryszard Koczorowski ${ }^{1, A, E}$, Barbara Dorocka-Bobkowska ${ }^{1, F}$ \\ 1 Department of Gerodontology and Oral Pathology, Poznan University of Medical Sciences, Poland \\ ${ }^{2}$ Mechanical Engineering Faculty, Lublin University of Technology, Poland \\ A - research concept and design; $\mathrm{B}$ - collection and/or assembly of data; $\mathrm{C}$ - data analysis and interpretation; \\ $\mathrm{D}$ - writing the article; $\mathrm{E}$ - critical revision of the article; $\mathrm{F}$ - final approval of the article
}

Address for correspondence

Rafał Brożek

E-mail: broz@ump.edu.pl

Funding sources

None declared

Conflict of interest

None declared

Received on November 21, 2019

Reviewed on February 6, 2020

Accepted on March 2, 2020

Published online on September 30, 2020

Cite as

Brożek R, Pałka K, Koczorowski R, Dorocka-Bobkowska B.

Effect of artificial saliva on the mechanical properties of a polymer material reinforced with fiber, used in esthetic tooth restorations. DentMed Probl. 2020;57(3):261-267. doi:10.17219/dmp/118642

DOI

$10.17219 / \mathrm{dmp} / 118642$

Copyright

๑ 2020 by Wroclaw Medical University

This is an article distributed under the terms of the

Creative Commons Attribution 3.0 Unported License (CC BY 3.0)

(https://creativecommons.org/licenses/by/3.0/).

\begin{abstract}
Background. The oral environment can negatively affect the physical properties of fiber-reinforced composite (FRC) materials, which can lead to the deterioration of mechanical stability and reduce the span of their clinical usefulness.

Objectives. The aim of this study was to determine the influence of artificial saliva on the selected mechanical properties of FRC.

Material and methods. The core of the polymer material selected for the study was a bundle of ultrahigh-molecular-weight polyethylene (UHMWPE) fibers. Fourteen samples were stored in an incubator at $37^{\circ}$, in $20 \mathrm{~mL}$ of artificial saliva solution, and weighed on days 1 and 28. At the same time, mechanical tests were performed, including the measurements of Young's modulus, tensile stress, maximum tensile force, and tensile deformation.
\end{abstract}

Results. The analysis of basic statistics together with the results of the Shapiro-Wilk test and the distribution of Spearman's tho coefficient showed a strong negative relationship between the pair of variables - tensile deformation and the sorption of synthetic saliva. The results related to Young's modulus of elasticity and tensile stress were not statistically significant.

Conclusions. Water penetration into the space between the fibers does not adversely affect the mechanical properties of the material tested. In the static tensile test, high and desired mechanical strength was observed, which may justify the effective use of this type of material in clinical practice and may be a good alternative to prosthetic restorations, whose retention is obtained only through a mechanical connection with the abutment tooth.

Key words: absorption, artificial saliva, mechanical stresses, composite materials

Słowa kluczowe: absorpcja, sztuczna ślina, naprężenia mechaniczne, materiały kompozytowe 


\section{Introduction}

High strength and low weight make fiber-reinforced composite (FRC) materials an effective alternative to other prosthetic solutions. A fiber-reinforced composite is a material made of fibers (the reinforcing phase) and a resin polymer matrix (the organic phase). The polymer matrix constitutes a structural basis for the reinforcing fibers, protects them against occlusal trauma and transfers external tension to them. Moreover, the polymer resin combines with the luting cement and gives the material a desired shape. Introducing fibers of a high elastic modulus into a soft matrix improves the strength and stiffness of the material, ensuring excellent mechanical properties of the composite in selective directions. Long-term loading thereof has become possible in situations in which so far the application of conventional fixed dentures has only been recommended. ${ }^{1}$

Ultra-high-molecular-weight polyethylene (UHMWPE) fibers, which reinforce the material, are characterized by an extremely high strength-to-weight ratio and great abrasion resistance. ${ }^{2}$ The lack of active chemical groups in UHMWPE (ester, amide or hydroxyl ones) results in its resistance to the activity of water, most chemical substances, UV radiation, and microorganisms. Under loading, this polymer undergoes elongation, constant in time as long as the applied force works. Ultra-high-molecularweight polyethylene fibers are non-polar, characterized by low surface energy values; nevertheless, their inertness makes the adhesion of UHMWPE to the polymer matrix hard to achieve., ${ }^{3,4}$ In order to improve the strength of the bond between the fibers and the organic matrix, the surfaces of the fibers are modified. ${ }^{5}$ All ways of activating UHMWPE lead to surface oxidation by increasing the number of the polar functional groups. The oxidation reaction changes energy and surface affinity; what undergoes change as well is the strength of the bond with some hydrophilic polymer systems, in contrast to unmodified fibers, and wettability in relation to non-activated polymers, which may lead to the progressive damage of the material, consisting in a loss of the cohesion of the fibers and the organic matrix, resulting from the changeable straining forces affecting them. ${ }^{6}$

The organic matrix of FRC may undergo hydrolysis and absorb water to various degrees, depending on its chemical composition. The water molecules diffusing into the spaces between the polymer chains may cause changes in the material dimensions. Such loosening of the spatial polymer network often translates into changes in the composite parameters, including its mechanical strength. The FRC organic matrix absorbs water by diffusion. Water molecules penetrate into the free spaces created between the chains of the polymer macromolecules, which results in loosening the polymer network. Changes in the volume and dimensions of the organic matrix are usually slight and can be reversible. However, the exploitation of the material in the humid and changeable oral environment may cause irreversible changes in the physical and chemical parameters of the composite material. ${ }^{4,7}$

The process of the modification of the fiber surfaces in an environment of increased humidity may contribute to the deterioration of physical parameters, such as tensile strength and the longitudinal modulus of elasticity. Such changes in the properties of FRC materials may seriously weaken stability in the changeable and difficult oral environment. Moreover, they may lead to the shortening of the clinical life span and limit the possibility of applying the materials in medical and dental practice.

Therefore, it seems justified to conduct research on water sorption and to determine its influence on changes in the selected strength characteristics of a polymer FRC material used in dentistry to build prosthetic restorations.

\section{Material and methods}

A ready-to-use FRC product (ARKONA LFS, Nasutów, Poland), Lot 2018-08-01, was used for the study. The core of the FRC is a bundle of polyethylene fibers of ultra-high molecular weight, $60 \mathrm{~mm}$ in length, made up of approx. 1,000 single filaments, each $5-10 \mu \mathrm{m}$ in diameter, whose surfaces were physically activated, and then impregnated with a mixture of methacrylate resins of low viscosity and low molecular weight. The polyethylene filaments, constituting about $30 \%$ of the volume of the product, are embedded in a microhybrid composite of increased mechanical resistance. The layers of the composite above and under the bundle of UHMWPE filaments are about 0.3-millimeter thick. The chemical composition of the composite material used in the study is shown in Table 1. The modification of the UHMWPE bundle by means of the resin impregnation preceded by the physical activation of the surfaces of the filaments was aimed at ensuring adhesion between the fibers and the composite material, resulting in the improvement of the mechanical parameters and the performance of the FRC produced in this way.

Prior to the tests, all samples were conditioned in $20 \mathrm{~mL}$ of artificial saliva, which had been obtained by dissolving chemical compounds in $1 \mathrm{dm}^{3}$ of distilled water in the following quantities: $\mathrm{NaCl}(0.4 \mathrm{~g}), \mathrm{KCl}(0.4 \mathrm{~g}), \mathrm{NaOH}$ (0.05 g), $\mathrm{CaCl}_{2} \cdot 2 \mathrm{H}_{2} \mathrm{O}(0.22 \mathrm{~g}), \mathrm{NaH}_{2} \mathrm{PO}_{4}(0.12 \mathrm{~g})$, and urea $(1 \mathrm{~g})$, at a temperature of $37^{\circ} \mathrm{C}$, for $24 \mathrm{~h}$.

Table 1. Chemical composition of the composite material used in the study

\begin{tabular}{|c|c|c|c|}
\hline $\begin{array}{c}\text { Type } \\
\text { of the material }\end{array}$ & $\begin{array}{l}\text { Organic } \\
\text { matrix }\end{array}$ & Filler & Manufacturer \\
\hline $\begin{array}{l}\text { Microhybrid } \\
\text { composite }\end{array}$ & $\begin{array}{l}\text { dimethacrylates: } \\
\text { Bis-GMA, UDMA, } \\
\text { TEGDMA }\end{array}$ & $\begin{array}{l}\text { Ba-Al-F-silicate } \\
\text { glass, pyrogenic } \\
\text { silica powder }\end{array}$ & $\begin{array}{c}\text { ARKONA LFS, } \\
\text { Nasutów, } \\
\text { Poland }\end{array}$ \\
\hline
\end{tabular}

Bis-GMA - bisphenol A-glycidyl methacrylate; UDMA - urethane dimethacrylate; TEGDMA - triethylene glycol dimethacrylate. 


\section{Mechanical studies}

The mechanical properties of the material were determined during the static tensile test with the use of the Instron 5969 machine (Instron, Norwood, USA). In the study, 14 samples of the tested material were used; 2 extreme results were rejected. The sample, which was $2.33 \pm 0.12 \mathrm{~mm}$ wide and $0.856 \pm 0.064 \mathrm{~mm}$ thick, and whose measuring length was $50 \mathrm{~mm}$, was elongated along its longitudinal axis at a constant clamp movement speed of $1 \mathrm{~mm} / \mathrm{min}$. The test was continued until a $20 \%$ decrease in the material strength was accomplished. The tests were performed on the $1^{\text {st }}$ and the $28^{\text {th }}$ day of the experiment. The following parameters were measured:

- the longitudinal modulus of elasticity (Young's modulus) - a property that measures the elasticity of a material when stretched, expressing the relationship between relative linear deformation and the strain which occurs for elastic deformations, individual for a given material; the value thereof was calculated from the following equation:

$$
E_{t}=\frac{\sigma_{2}-\sigma_{1}}{\varepsilon_{2}-\varepsilon_{1}} \quad[\mathrm{MPa}]
$$

where:

$E_{t}$ - modulus of elasticity under strain [MPa],

$\sigma_{1}-$ strain measured at the deformation value $\varepsilon_{1}=0.0005(0.05 \%)$ [MPa],

$\sigma_{2}$ - strain measured at the deformation value $\varepsilon_{2}=0.0020(0.20 \%)[\mathrm{MPa}]$

- tensile stress, which is the tensile force affecting the initial cross-section surface unit, applied to the measuring length; its value was calculated from the following equation:

$$
\sigma=\frac{F}{A}[\mathrm{MPa}]
$$

where:

$\sigma-$ given stress value $[\mathrm{MPa}$,

$F$ - corresponding force $[\mathrm{N}]$,

$A$ - initial moulding cross-section area $\left[\mathrm{mm}^{2}\right]$;

- maximum tensile force $F_{\text {max }}$, recorded by the measuring device at the moment when the sample is broken;

- deformation under tension (displacement), i.e., the linear elongation of the sample during the measurement, whose value was calculated from the following formula:

$$
\varepsilon_{t}=\frac{L_{t}}{L}
$$

where:

$\varepsilon_{t}-$ nominal deformation, expressed in a dimensionless quantity,
$L_{t}$-increase in the distance between the clamps since the beginning of the test [mm],

$L$ - distance between the clamps [mm].

\section{Water sorption}

Seven samples with dimensions of $15 \mathrm{~mm} \times 2.5 \mathrm{~mm} \times$ $1.4 \mathrm{~mm}$ were prepared. Each of the samples was stored in an incubator for 28 days, at a temperature of $37^{\circ} \mathrm{C}$, in $20 \mathrm{~mL}$ of artificial saliva. The samples were weighed on the $1^{\text {st }}$ and the $28^{\text {th }}$ day of the experiment with an electronic balance accurate to $0.0001 \mathrm{~g}$. The obtained results were marked $W_{1}$ and $W_{28}$, respectively. Each time before the measurement was made, the samples were dried with tissue paper until no traces of moisture were visible on their surfaces.

\section{Results}

In order to investigate the relationship between the variables taken into consideration in the study, statistical analyses were conducted with the use of the TIBCO Statistica ${ }^{\circledR}$ v. 13.3 software (TIBCO Software, Inc., Palto Alto, USA). The analysis of basic descriptive statistics together with the Shapiro-Wilk test as well as the analysis of the Pearson correlation coefficient, Spearman's rho, and the trend line adjustment analysis were carried out. The significance level was established at the classic threshold $\alpha=0.05$.

\section{Basic descriptive statistics of the material properties}

At the beginning, the basic descriptive statistics of the quantitative variables under study were calculated, along with performing the Shapiro-Wilk test, examining the normality of the distribution of these variables. This test showed that the distribution of the maximum tensile force value $F_{\max }$ did not differ significantly from the normal one. A different situation was observed for the other quantitative variables included in the study. Therefore, the skewness values were analyzed and were found to range from -2 to +2 for sorption $\omega$, so it might be assumed that the distribution was similar to the normal one. ${ }^{8}$ The distributions of the remaining variables examined in the study, i.e., Young's modulus $E_{t}$, tensile stress $\sigma$ and tensile deformation $\varepsilon_{t}$, were significantly asymmetrical in relation to the average. That is why the correlations between sorption and the enumerated variables were subjected to nonparametric tests. In the case of the correlation between sorption and maximum tensile force, parametric tests were applied, having met the other assumptions. The results are presented in Table 2 . 
Table 2. Basic statistics of the parameters tested for the examined material

\begin{tabular}{|c|c|c|c|c|c|c|c|c|c|}
\hline Variable & $M$ & $M e$ & $S D$ & Skewness & Kurtosis & $\begin{array}{l}\text { Lowest value } \\
\text { of the distribution }\end{array}$ & $\begin{array}{l}\text { Highest value } \\
\text { of the distribution }\end{array}$ & $\begin{array}{c}\text { Result of the } \\
\text { Shapiro-Wilk test }\end{array}$ & $p$-value \\
\hline$E_{t}[\mathrm{MPa}]$ & $9,781.25$ & $5,074.44$ & $10,349.31$ & 2.45 & 7.16 & $2,093.77$ & $42,338.38$ & 0.699 & $<0.001^{*}$ \\
\hline$F_{\max }[\mathrm{N}]$ & 74.99 & 70.45 & 38.61 & 0.73 & -0.75 & 32.39 & 145.97 & 0.894 & 0.076 \\
\hline$\varepsilon_{t}$ & 0.03 & 0.02 & 0.02 & 2.73 & 9.00 & 0.01 & 0.09 & 0.695 & $<0.001^{*}$ \\
\hline
\end{tabular}

$E_{t}-$ Young's modulus of elasticity; $\sigma$ - tensile stress; $F_{\text {max }}$ - maximum tensile force; $\varepsilon_{t}$ - tensile deformation; $\omega$ - sorption; $M-$ mean; $M e-$ median; SD - standard deviation; ${ }^{*}$ statistical significance.

\section{Relationship between the value of maximum tensile force and sorption}

Initially, the hypothesis stating that there was a relationship between the value of maximum tensile force and sorption was verified. In order to do that, the analysis of the Pearson correlation coefficient was conducted by comparing the value of maximum tensile force with the sorption value, calculated from the following formula:

$$
\omega=\frac{W_{28}-W_{1}}{V}\left[\mu \mathrm{g} / \mathrm{mm}^{3}\right]
$$

where:

$\omega$ - sorption $\left[\mu \mathrm{g} / \mathrm{mm}^{3}\right]$;

$W_{1}$ - weight of the sample on day $1[\mu \mathrm{g}]$;

$W_{28}$ - weight of the sample on day $28[\mu \mathrm{g}]$;

$V$-volume $\left[\mathrm{mm}^{3}\right]$.

A statistically insignificant result was obtained. Then, it should be acknowledged that there was no relationship between the investigated variables. The relationship between maximum tensile strength and sorption is presented in Table 3.

Table 3. Relationship between maximum tensile strength and sorption

\begin{tabular}{|l|c|c|}
\multicolumn{1}{c|}{ Statistics } & $F_{\max }$ & $\begin{array}{c}\omega \\
{\left[\mu \mathrm{g} / \mathrm{mm}^{3}\right]}\end{array}$ \\
\hline Pearson's correlation coefficient & {$[\mathrm{N}]$} & -0.322 \\
$p$-value & \multicolumn{2}{|c|}{0.241} \\
\hline
\end{tabular}

\section{Relationship between sorption,} the value of Young's modulus, tensile stress, and tensile deformation for the tested material

Next, it was checked whether or not there was a relationship between the value of Young's modulus, tensile stress and tensile deformation for the tested material and sorption. In order to determine whether there is a relationship between the examined variables and sorption, the correlation analysis was conducted, similarly to the previous stage. However, as the distributions of the aforementioned variables were significantly asymmetrical in relation to the average, nonparametric tests were carried out, i.e., the analysis of Spearman's rank correlation coefficient. A statistically significant result was obtained for the following pair of variables - tensile deformation and sorption, which meant that there was a statistically significant, strong negative relationship between the investigated variables. It should, then, be understood that the greater the sorption, the lower the tensile deformation values would be. The trend line adjustment analysis showed that the relationship between the 2 variables could be expressed by the following formula:

$$
\varepsilon_{t}=\omega \times-4.1523 \times 10^{-5}+0.0289
$$

In the case of the other variables, statistically significant results were not obtained. Then, it should be assumed that the sorption value did not affect the values of the other variables - Young's modulus and tensile stress. The results are presented in Table 4 and Fig. 1.

Table 4. Relationship between Young's modulus, tensile stress and tensile deformation for the tested material and sorption

\begin{tabular}{|l|c|c|c|c|c|c|}
\hline Statistics & $\begin{array}{c}E_{t} \\
{[\mathrm{MPa}]}\end{array}$ & $\begin{array}{c}\omega \\
{\left[\mu \mathrm{g} / \mathrm{mm}^{3}\right]}\end{array}$ & $\begin{array}{c}\sigma \\
{[\mathrm{MPa}]}\end{array}$ & $\begin{array}{c}\omega \\
{\left[\mu \mathrm{g} / \mathrm{mm}^{3}\right]}\end{array}$ & $\varepsilon_{t}$ & $\begin{array}{c}\omega \\
{\left[\mu \mathrm{g} / \mathrm{mm}^{3}\right]}\end{array}$ \\
$\begin{array}{l}\begin{array}{l}\text { Spearman's } \\
\text { rho correlation }\end{array} \\
0.261\end{array}$ & 0.075 & -0.539 \\
$p$-value & 0.348 & 0.791 & $0.038^{*}$ \\
\hline
\end{tabular}

* statistical significance.

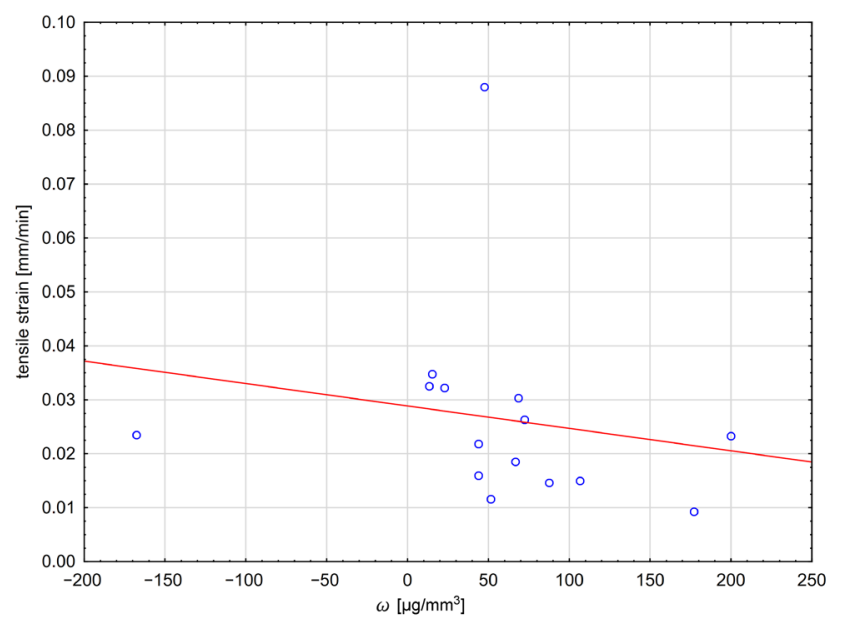

Fig. 1. Effect of sorption on the tensile strain of the selected material 


\section{Discussion}

Fiber-reinforced composites are a group of prosthetic materials, which is increasingly treated as an alternative to traditional ceramic or metal restoration materials in dentistry. In the course of treatment with the use of a minimally invasive preparation technique, it has become possible to make lightweight prosthetic restorations, resembling natural dentition and, at the same time, ensuring desired strength and biocompatibility, cemented adhesively, not only mechanically. Lehmann et al. ${ }^{9}$ as well as Behr et al. ${ }^{10}$ admit that the incorporation of fibers in an organic matrix enhances the fracture resistance of the composite materials, and static tests have confirmed an increase in their tensile strength. ${ }^{11}$ Some authors have shown that the location and orientation of the fibers in the material also affect its mechanical properties, ${ }^{12}$ and the clinical effectiveness of such materials has been amply confirmed in the literature as well..$^{13,14}$

Stress and the modulus of elasticity are parameters determining static mechanical properties. When external forces, generated, for example, during chewing, are transferred to a tooth or a dental restoration, i.e., there are stress conditions, energy is stored in the structure of the material. Due to the stress emerging within its structure, the material changes its shape or dimensions. ${ }^{15}$

The values of Young's modulus of elasticity and tensile stress obtained in the fiber unidirectional tensile test are presented in Table 2. On their basis, it may be stated that the material under study satisfies the requirements for polymer materials applied in dentistry to restore and make prosthetic crowns and bridges which are permanently attached to the pillar tooth, without the need for mechanical retention. In mechanical tests, tensile strength should be at least $50 \mathrm{MPa}$ whereas the strength of the connection with the experimental tooth should not be less than $5 \mathrm{MPa} .{ }^{6,16}$ The tested material is elastic and, at the same time, resistant to breaking.

Many factors influence the mechanical properties of FRC. These are the strength parameters of both the fibers and the polymer matrix in which they are embedded, the extent to which the fibers are integrated with the organic resin as well as their number, length, diameter, and spatial orientation in the material. On the basis of the images obtained with the use of a scanning electron microscope (SEM) and an optical microscope, it was concluded that the fibers were evenly embedded in the organic matrix. The attempt at breaking the material after having frozen it with liquid nitrogen, undertaken in order to make the composite fracture visible, was successful despite high strength parameters (Fig. 2).

Obtaining a fiber with an unusually ordered chain, as a result of forcing and elongating polyethylene of a molecular weight equal to approx. 300,000 Da, has been great technological progress. The polymer building the structure of a polyethylene fiber makes parallel chains

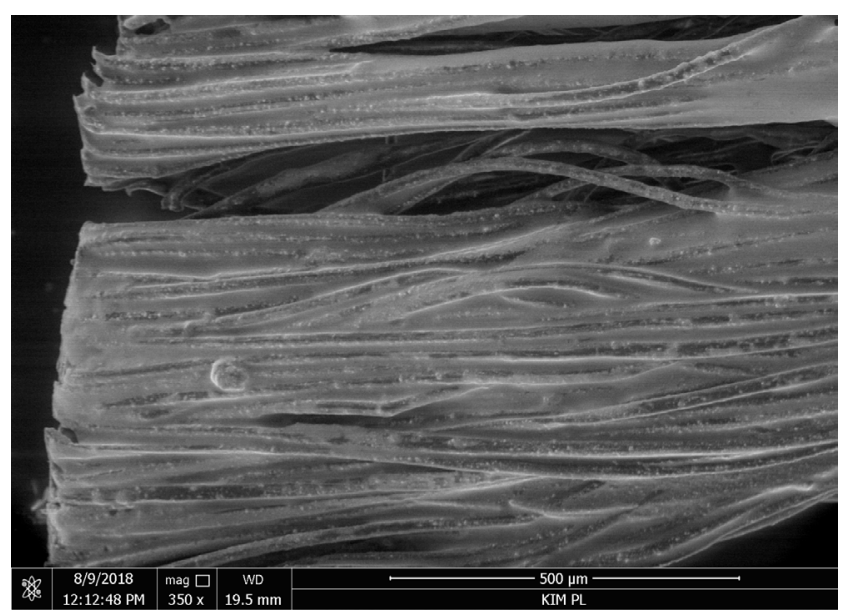

Fig. 2. Bundle of parallel fibers embedded in the composite Magnification $\times 350$.

of an orientation degree $>95 \%$ and crystallinity $>85 \%$, which distinguishes it from para-aramid fibers, whose strength results mainly from a large number of intermolecular hydrogen bonds. Polymers containing aromatic groups have strong affinity for aromatic solvents whereas aliphatic UHMWPE is resistant to their activity. ${ }^{5}$

The process of the modification of the UHMWPE surface is aimed at improving the integration of the fibers with the organic matrix. It causes changes in the molecular structure of the fibers. At the initial stage, the phenomena also happen at the boundary of the individual phases, leading to an improvement in the material properties, in particular mechanical strength, which has been confirmed in the conducted studies. This happens through the additional cross-linking of the structure. In a longer time period, however, the depolymerization, destruction and decomposition of the polymer material to a monomer can be observed, so the material is degraded. Further research is, therefore, recommended in order to confirm a possible decrease in the mechanical properties with time. ${ }^{17}$ Scanning electron microscopy confirms the high efficiency of the connection of the composite with the filaments in the tested samples (Fig. 3).

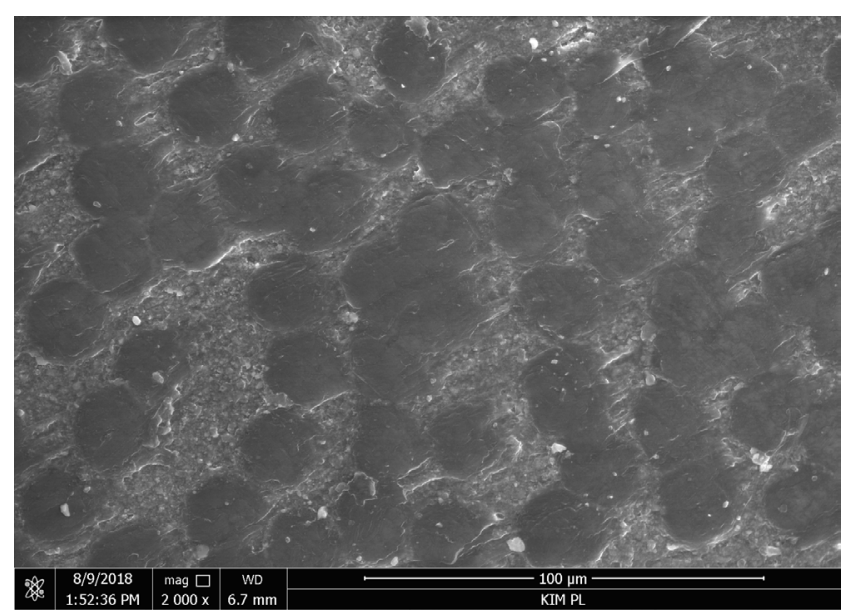

Fig. 3. Cross-section of a UHMWPE filament sealed with the composite material Magnification $\times 2,000$ 
Water is absorbed into the organic matrix by diffusion. The bidirectional migration of water molecules and residual monomers - the unreacted products of the polymerization reaction - loosely connected with the matrix, is caused by the kinetic energy of the individual molecules and continues until the dynamic balance of the system is achieved. The weight of FRC remains constant then and, basically, does not undergo further changes. ${ }^{18}$

In the study, the phenomenon of water absorption took place in equal time periods, and the process was not statistically significant in all the analyzed time intervals. In the course of the experiment, the changes corresponded to the state of intermolecular forces, canceling each other out, not causing the mutual exchange of weight. The quantity of the absorbed water rose proportionally to the growth of the polymer volume of the organic matrix, and decreased together with an increase in the number of the reinforcing fibers embedded in it. The quantity of the water absorbed by FRC should, then, be smaller in comparison with resins, in which the fillers are not continuous fibers, but inorganic glass particles, silica, etc., of different geometry. ${ }^{19}$ Storing a fiberglass-reinforced organic resin in artificial saliva for 180 weeks caused the strength of the material to deteriorate by $27 \% .^{20}$

A less effective connection between the reinforcing fibers and the organic matrix may lead to empty spaces, fractures and other defects in the structure of the material. Presumably, this phenomenon facilitates water penetration, which damages the links in the threedimensional (3D) polymer grid, thus destabilizing the material. ${ }^{21}$ According to Miettinen et al., an incoherent and non-homogeneous polymer bond with the fibers reinforcing the matrix in the structure of the material may result in empty spaces in the 3D spatial arrangement. ${ }^{19}$ The images obtained by Behr et al. with the use of SEM confirmed that the damage to and the physical flaws of the material caused by water molecules led to the deterioration of its mechanical properties. ${ }^{10}$ The study by Chai et al. showed that an improvement in the sorption properties might be achieved by prolonging the time of the irradiation of the material; a higher conversion level and a better density of the organic matrix crosslinking were then obtained. ${ }^{22}$

In the study, the phenomenon of water absorption took place in equal time periods, yet the process was not statistically significant. The examined material satisfied the assumptions of the following norm: ISO 10477:2018 Dentistry - Polymer-based crown and veneering materials, which states that water absorption should not exceed $40 \mu \mathrm{g} / \mathrm{mm}^{3}$ within 1 month of the experiment. ${ }^{23}$ The good sorption properties of the FRC material (low water sorption), in which the fibers are arranged unidirectionally in the form of a longitudinally oriented bundle, may prove the good preparation of the polyethylene fibers and the effective connection thereof with the dimethacrylate grid.

\section{Conclusions}

On the basis of the conducted strength tests, high and desired mechanical strength was observed in the tensile tests, which may justify the effective use of this type of fiber in clinical practice. The phenomena of saturation and the penetration of the resin into the spaces between the fiber bundles, occurring in the process of their physical modification, did not negatively influence the mechanical properties of the material under study. Water sorption did not negatively affect the mechanical properties of the FRC material. Fiber-reinforced composites can be an alternative to prosthetic restorations, whose retention is obtained only through mechanical interlocking to the abutment tooth.

\section{ORCID iDs}

Rafał Brożek (1) https://orcid.org/0000-0003-0917-9214 Krzysztof Pałka (1) https://orcid.org/0000-0003-4920-4613

Ryszard Koczorowski (10 https://orcid.org/0000-0003-4456-1347

Barbara Dorocka-Bobkowska (1) https://orcid.org/0000-0003-3659-7761

\section{References}

1. Sokołowski JŁ, Szynkowska MI, Kleczewska J, et al. Evaluation of resin composites modified with nanogold and nanosilver. Acta Bioeng Biomech. 2014;16(1):51-61.

2. Sui G, Zhong WH, Ren X, Wang XQ, Yang XP. Structure, mechanical properties and friction behavior of UHMWPE/HDPE/carbon nanofibers. Mater Chem Phys. 2009;115(1):404-412.

3. Oosterom R, Ahmed TJ, Poulis JA, Bersee HEN. Adhesion performance of UHMWPE after different surface modification techniques. Med Eng Phys. 2006;28(4):323-330.

4. Łukomska-Szymańska M, Kleczewska J, Nowak J, et al. Mechanical properties of calcium fluoride-based composite materials. Biomed Res Int. 2016;2016:2752506.

5. Debnath S, Ranade R, Wunder SL, Baran GR, Zhang J, Fisher ER. Chemical surface treatment of ultrahigh molecular weight polyethylene for improved adhesion to methacrylate resins. J Appl Polym Sci. 2005;96(5):1564-1572.

6. Bahramian N, Atai M, Naimi-Jamal MR. Ultra-high-molecularweight polyethylene fiber reinforced dental composites: Effect of fiber surface treatment on mechanical properties of the composites. Dent Mater. 2015;31(9):1022-1029.

7. Dorocka-Bobkowska B, Medyński D, Pryliński M. Recent advances in tissue conditioners for prosthetic treatment: A review. Adv Clin Exp Med. 2017;26(4):723-728.

8. George D, Mallery P. SPSS for Windows Step by Step: A Simple Guide and Reference. $11^{\text {th }}$ ed. Upper Saddle River, NJ: Prentice Hall; 2010:212-216.

9. Lehmann F, Eickemeyer G, Rammelsberg P. Fracture resistance of metal-free composite crowns - effects of fiber reinforcement, thermal cycling, and cementation technique. J Prosthet Dent. 2004;92(3):258-264.

10. Behr M, Rosentritt M, Latzel D, Kreisler T. Comparison of three types of fiber-reinforced composite molar crowns on their fracture resistance and marginal adaptation. J Dent. 2001;29(3):187-196.

11. Väkiparta M, Yli-Urpo A, Vallittu PK. Flexural properties of glass fiber reinforced composite with multiphase biopolymer matrix. J Mater Sci Mater Med. 2004;15(1):7-11.

12. Dyer SR, Lassila LVJ, Jokinen M, Vallittu PK. Effect of fiber position and orientation on fracture load of fiber-reinforced composite. Dent Mater. 2004;20(10):947-955.

13. Freilich MA, Meiers JC, Duncan JP, Eckrote KA, Goldberg AJ. Clinical evaluation of fiber-reinforced fixed bridges. J Am Dent Assoc. 2002;133(11):1524-1534;quiz 1540-1541.

14. Vallittu PK, Sevelius C. Resin-bonded, glass fiber-reinforced composite fixed partial dentures: A clinical study. J Prosthet Dent. 2000;84(4):413-418. 
15. Lassila V, Holmlund I, Koivumaa KK. Bite force and its correlations in different denture types. Acta Odontol Scand. 1985;43(3):127-132.

16. Wolff $D$, Coupek M, Erber $R$, et al. Effect of aqueous storage on original and repair bond strength and residual monomer release of fiber-reinforced composites. J Adhes Dent. 2016;18(6):535-543.

17. Vallittu PK. Some aspects of the tensile strength of unidirectiona glass fibre-polymethyl methacrylate composite used in dentures. J Oral Rehabil. 1998;25(2):100-105.

18. Sakaguchi RL, Powers JM. Craig's Restorative Dental Materials. $13^{\text {th }}$ ed. St. Louis, MO: Mosby; 2011:156-158.

19. Miettinen VM, Narva KK, Vallittu PK. Water sorption, solubility and effect of post-curing of glass fibre reinforced polymers. Biomaterials. 1999;20(13):1187-1194.

20. Vallittu PK. Effect of 180-week water storage on the flexural properties of E-glass and silica fiber acrylic resin composite. Int $J$ Prosthodont. 2000;13(4):334-339.

21. Vallittu PK. The effect of void space and polymerization time on transverse strength of acrylic-glass fibre composite. J Oral Rehabil. 1995;22(4):257-261.

22. Chai J, Takahashi Y, Kawaguchi M. The flexural strengths of denture base acrylic resins after relining with a visible-light-activated material. Int J Prosthodont. 1998;11(2):121-124.

23. https://www.iso.org/standard/68235.html. Accessed on February 10 2020. 
